\title{
Dynamic study of ammonium dawsonite doped with yttrium transformation at elevated temperatures
}

\author{
R. Lach • M. M. Bućko $\cdot$ K. Haberko • \\ M. Szumera $\cdot$ R. Gajerski
}

Received: 28 February 2012/ Accepted: 27 July 2012/Published online: 28 August 2012

(c) The Author(s) 2012. This article is published with open access at Springerlink.com

\begin{abstract}
Co-precipitation of alumina/YAG precursor from aluminum and yttrium nitrates solution with ammonium carbonate results in dawsonite $\left(\mathrm{NH}_{4} \mathrm{Al}(\mathrm{OH})_{2} \mathrm{CO}_{3}\right)$. Its crystallographic parameters differ from the compound precipitated without the yttrium additive. It indicates that yttrium ions become incorporated into the dawsonite structure. The DSC/TG and X-ray measurements show decomposition of dawsonite at elevated temperature resulting in $\gamma-\mathrm{Al}_{2} \mathrm{O}_{3}$ which transforms to $\delta$ and $\theta$ modifications at still higher temperatures. The full transformation to $\alpha-\mathrm{Al}_{2} \mathrm{O}_{3}$ and YAG occurs at temperatures higher than $1,230^{\circ} \mathrm{C}$.
\end{abstract}

Keywords Ammonium dawsonite - Co-precipitation · Alumina-YAG

\section{Introduction}

Mineral dawsonite $\left(\mathrm{NaAl}(\mathrm{OH})_{2} \mathrm{CO}_{3}\right)$ has been known since the nineteenth century. A variety of dawsonite-type structure compounds have been synthesized by different techniques with several incorporated cations: $\mathrm{K}^{+}, \mathrm{Ca}^{2+}, \mathrm{Mg}^{2+}$, $\mathrm{Ba}^{2+}, \mathrm{Sr}^{2+}, \mathrm{Co}^{2+}, \mathrm{Mn}^{2+} \mathrm{La}^{3+}, \mathrm{Cr}^{3+}, \mathrm{Fe}^{3+}$ [1]. The ammonia version of dawsonite $\left(\mathrm{NH}_{4} \mathrm{Al}(\mathrm{OH})_{2} \mathrm{CO}_{3}\right)$ was synthesized by Moringa et al. [2]. They introduced the aqueous solution of $\mathrm{NH}_{4} \mathrm{Al}\left(\mathrm{SO}_{4}\right)_{2}$ to the $\mathrm{NH}_{4} \mathrm{HCO}_{3}$ solution receiving the precipitate. They studied thermal decomposition of this precipitate to $\alpha-\mathrm{Al}_{2} \mathrm{O}_{3}$. Ammonia dawsonite occurred as the first product of precipitation

R. Lach $(\bowtie) \cdot$ M. M. Bućko · K. Haberko · M. Szumera

R. Gajerski

AGH University of Science and Technology,

Al. Mickiewicza 30, 30-059 Kraków, Poland

e-mail: radek.lach@poczta.fm from aqueous solution of $\mathrm{Al}\left(\mathrm{NO}_{3}\right)_{3}+\mathrm{Mg}\left(\mathrm{NO}_{3}\right)_{2}$ treated with $\left(\mathrm{NH}_{4}\right)_{2} \mathrm{CO}_{3}$ [3]. This study was devoted to the magnesium/aluminum spinel powder synthesis; $\mathrm{Mg} / \mathrm{Al}$ ratio corresponded to this one compound. After aging dawsonite of such a composition decomposed to ammonium dawsonite and also hydrotalkite $\left(\mathrm{Mg}_{6} \mathrm{Al}_{2}\left(\mathrm{CO}_{3}\right)(\mathrm{OH})_{16} \cdot 4 \mathrm{H}_{2} \mathrm{O}\right)$. $\mathrm{X}$-ray amorphous ammonia version of dawsonite appeared in some studies on YAG synthesis [4-6]. Precipitation from the relative nitrate solution with $\mathrm{NH}_{4} \mathrm{HCO}_{3}$ was applied in these works without, however, detailed information on thermal decomposition of this compound.

The study of the alumina-YAG system by precipitation of yttria precursor within alumina suspension leads to ceramic matrix composites of interesting mechanical properties [7]. YAG inclusions resulted from the reaction between $\alpha-\mathrm{Al}_{2} \mathrm{O}_{3}$ matrix and yttria during sintering.

Co-precipitation from aluminum and yttrium nitrates solution with $\left(\mathrm{NH}_{4}\right)_{2} \mathrm{CO}_{3}$ allowed us to obtain an intimate mixture in the alumina-yttria system. It proved to be another possibility of the synthesis of such powders and materials [8]. This paper is devoted to characterization of the co-precipitation product and its evolution at elevated temperature. According to our knowledge, the alumina/ yttria system prepared by co-precipitation with $\left(\mathrm{NH}_{4}\right)_{2} \mathrm{CO}_{3}$ and its thermal evolution has not yet been investigated by other researchers.

\section{Experimental}

Yttria of purity $99.9 \%$ (main impurities $\mathrm{Cr}_{2} \mathrm{O}_{3}-0.04$ wt $\%$ and $\mathrm{Ag}_{2} \mathrm{O}-0.03 \mathrm{wt} \%$ ) was dissolved in nitric acid of analytical quality and mixed with the aluminum nitrate solution also of analytical quality. Concentration of the $\mathrm{Al}\left(\mathrm{NO}_{3}\right)_{3}+\mathrm{Y}\left(\mathrm{NO}_{3-}\right)_{3}$ solution was $0.62 \mathrm{~mol} / \mathrm{L}$. The $\mathrm{Al} / \mathrm{Y}$ 
ratio corresponded to 20 vol. $\%$ YAG $(22,2 \mathrm{wt} \%)$ after the reaction within the system. The mutual solution of both nitrates was introduced to the vigorously stirred solution of ammonium carbonate; $\mathrm{pH}$ of the suspension was kept constant during the process at the level of 8.5. Under such conditions the quantitative yttrium and aluminum precipitation occurs, as determined by the ICP filtrate analysis. The surplus volume of the liquid was removed by the vacuum filtration, using Buechner funnel. The precipitate was washed three times with ethyl alcohol and then dried at $110^{\circ} \mathrm{C}$ for $12 \mathrm{~h}$. Washing with alcohol, due to its low surface tension, allows fluffy precipitate to be received [9]. For comparison the same procedure was applied using the $\mathrm{Al}\left(\mathrm{NO}_{3}\right)_{3}$ solution with no yttrium additive.

DSC/TG measurements (Netzsch STA 449 F3 Jupiter) were used to follow the phenomena occurring during heat treatment of the powder sample. The rate of temperature increase was $10^{\circ} \mathrm{C} \mathrm{min}^{-1}$. Measurements were performed in flowing $\left(40 \mathrm{~cm}^{3} \mathrm{~min}^{-1}\right)$ synthetic air atmosphere. Based on these measurements, the samples were prepared by their heating to the predetermined temperatures corresponding to the particular heat effects and quickly cooled down. Rate of temperature decrease from 800 to $400{ }^{\circ} \mathrm{C}$ was about $50{ }^{\circ} \mathrm{C} \mathrm{min}^{-1}$. At still higher temperature it was even faster. The phase composition of the samples, heated with the DSC/TG equipment to the predetermined temperatures corresponding to the particular heat effects, was determined by the X-ray diffraction $(\mathrm{Cu} \mathrm{K} \alpha$ radiation, equipment X'PertPro, Panalytical). Fast sample cooling allows us to assume that phase composition at predetermined temperature is freeze down. The chemical analysis of gasses emitted by the sample was useful in understanding the decomposition process of the co-precipitated product at elevated temperature. Quadrupole mass spectrometer (Mass Spectrometer QMD 300 Thermostar) was used. Helium atmosphere was applied to avoid a reaction of the emitted gasses with $\mathrm{O}_{2}$ or $\mathrm{N}_{2}$. Before measurements apparatus was washed for $24 \mathrm{~h}$ with $\mathrm{He}$ of $10 \mathrm{ppm} \mathrm{H}_{2} \mathrm{O}$ content. Ionic currant corresponding to this water contamination was subtracted from the analysis result.

\section{Results and discussion}

Figure 1 shows $\mathrm{X}$-ray diffraction pattern of the material co-precipitated with yttrium additive. The pattern agrees with the data corresponding to ammonium dawsonite, $\mathrm{NH}_{4} \mathrm{Al}(\mathrm{OH})_{2} \mathrm{CO}_{3}$ (orthorhombic symmetry, space group $\mathrm{Cmcm}$ ). The same concerns the material precipitated without yttrium additive. Identification was made on the basis of ICSD collection code 010027 and data of Ref. [10]. It is worth noticing that no reflections that could be attributed to the yttrium containing phase are observed.
It suggests that yttrium ions are built into the dawsonite structure or remain in the X-ray amorphous form. However, the former eventuality seems to be corroborated by the essentially different lattice parameters of the material co-precipitated with yttrium and the one prepared by the same technique but without this additive (Table 1). The differences surpass an error of these measurements $(0.0002 \mathrm{~nm})$. Yttrium additive affects also the dawsonite crystallite sizes assessed on the basis of the (110) reflection broadening, using the Scherrer formula. The one with yttrium and without this additive show values of 6.1 and $12.8 \mathrm{~nm}$, respectively. It indicates that yttrium ions slow down the dawsonite crystallite growth. Probably the X-ray amorphous dawsonite occurring in the study on YAG synthesis [4-6] should be related to a much higher yttrium concentration than in this study.

Figure 2 demonstrates results of the DSC/TG measurements of the material co-precipitated with yttrium (a) and containing only pure dawsonite with no yttrium additive. At low temperatures a strong endothermic effect accompanied by weight losses occurs. Weight loss in the temperature range $20-200{ }^{\circ} \mathrm{C}$ equals to 53 and $49 \%$ for the system without yttrium and with yttrium additive, respectively. As indicated by the analysis of gasses emitted by the samples these weight losses should be attributed to the $\mathrm{NH}_{3}, \mathrm{CO}_{2}$, and $\mathrm{H}_{2} \mathrm{O}$ discharge (Fig. 3). At temperature higher than about $200{ }^{\circ} \mathrm{C}$ no $\mathrm{NH}_{3}$ and $\mathrm{CO}_{2}$ occurs. However, at temperature range of $200-450{ }^{\circ} \mathrm{C}$ emission of $\mathrm{H}_{2} \mathrm{O}$ is observed and it can presumably be attributed to the water desorption from the system. Weight losses in this temperature range were 9 and $8 \%$ for the system without yttrium and with yttrium additive, respectively. The temperature of the effects differs by a few degrees centigrade for the both systems (see Fig. 2a, b). Lower peak temperature is observed in yttrium containing material. These effects

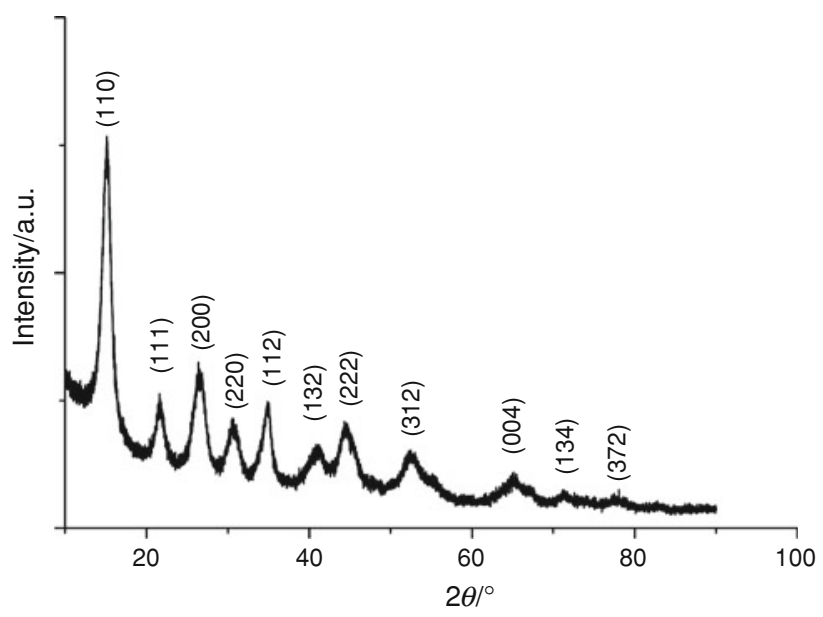

Fig. 1 X-ray diffraction patterns of materials co-precipitated with yttrium additive 
Table 1 Crystallographic parameters of dawsonite

\begin{tabular}{llll}
\hline Dawsonite & $a / \mathrm{nm}$ & $b / \mathrm{nm}$ & $c / \mathrm{nm}$ \\
\hline With yttrium & 0.66724 & 1.19030 & 0.57105 \\
Without yttrium & 0.66267 & 1.19350 & 0.57148
\end{tabular}
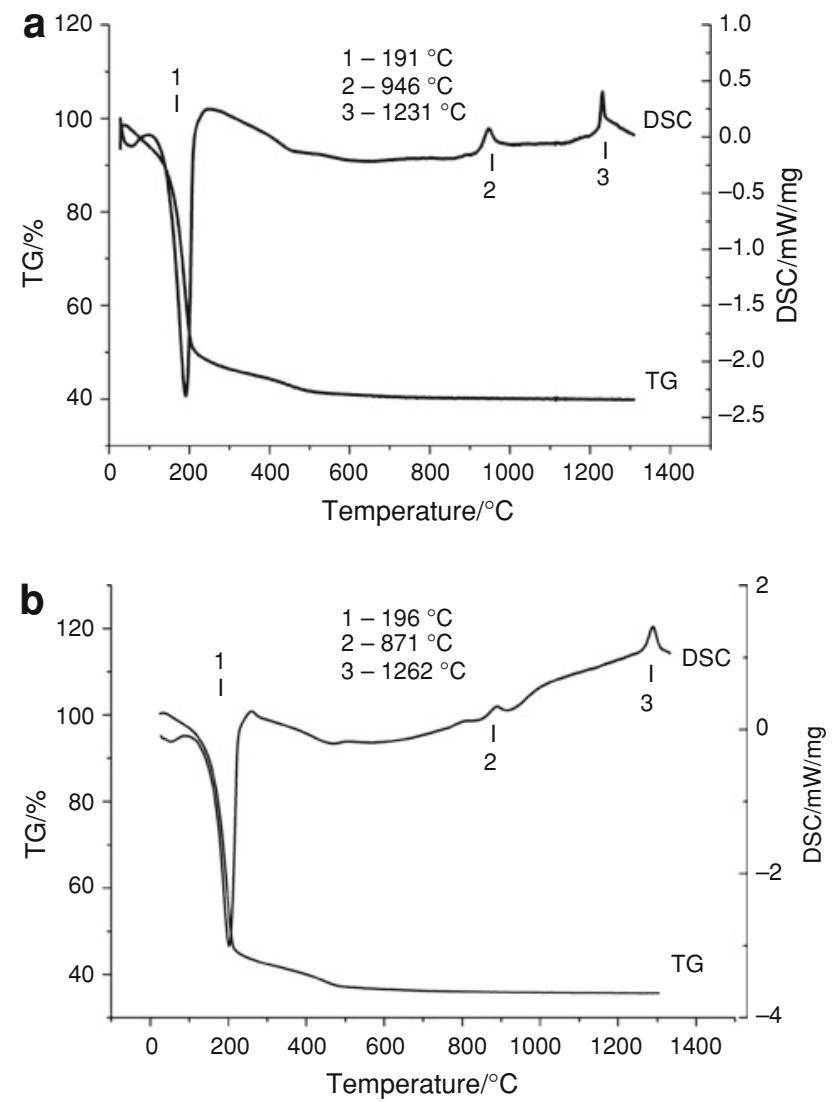

Fig. 2 DSC/TG curves of the material precipitated with yttrium (a) and without this additive (b)

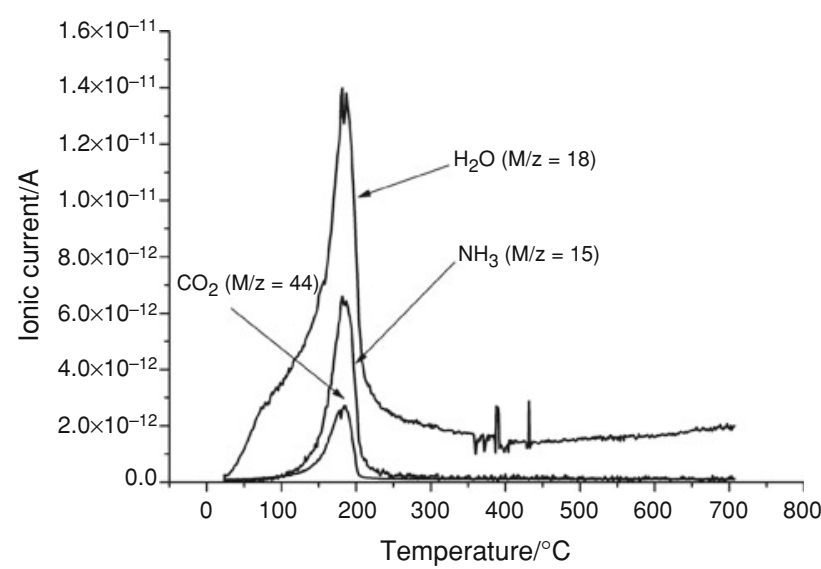

Fig. 3 Mass spectrographic analyses of gasses emitted at elevated temperature from the sample co-precipitated with yttrium additive result from the dawsonite decomposition as substantiated by the $\mathrm{H}_{2} \mathrm{O}, \mathrm{NH}_{3}$, and $\mathrm{CO}_{2}$ emission.

Exothermic effect temperatures shown by the DSC curves (Fig. 2) of the material co-precipitated with $\mathrm{Y}$ additive and without this element differ essentially; peak temperature of the former one is at $946{ }^{\circ} \mathrm{C}$ and the latter, $871{ }^{\circ} \mathrm{C}$. In order to identify the reason of these effects both samples were heated up to 800 and $1,100{ }^{\circ} \mathrm{C}$, i.e., lower and higher than the effects under discussion. This was performed using the DSC/TG equipment. X-ray diffractions shown in Fig. 4, represent a sample containing yttrium additive. Again, no reflections which could be attributed to the yttrium containing phase could be observed neither at $800{ }^{\circ} \mathrm{C}$ nor at $1,100{ }^{\circ} \mathrm{C}$. The material calcined at $800{ }^{\circ} \mathrm{C}$ shows $\gamma-\mathrm{Al}_{2} \mathrm{O}_{3}$ only. Heat treatment at $1,100{ }^{\circ} \mathrm{C}$ leads to alumina transformations: $\delta-\mathrm{Al}_{2} \mathrm{O}_{3}$ and $\theta-\mathrm{Al}_{2} \mathrm{O}_{3}$ phases appear. So we can conclude that the exothermic effect corresponds to the phase transformation: $\gamma-\mathrm{Al}_{2} \mathrm{O}_{3} \rightarrow \delta-\mathrm{Al}_{2} \mathrm{O}_{3}+\theta-\mathrm{Al}_{2} \mathrm{O}_{3}$. The same is observed in the system without yttrium additive though in the case of pure alumina system temperature of this transformation is lower (cf. Fig. 2).

Crystallization of $\mathrm{Y}_{2} \mathrm{O}_{3}$ was observed at $800{ }^{\circ} \mathrm{C}$ during studies of YAG synthesis by co-precipitation with $\mathrm{NH}_{4} \mathrm{HCO}_{3}$ [4]. It cannot be excluded that an essentially higher concentration of yttrium in the case of YAG synthesis than in the present investigation shifts at least a part of yttrium component of the system towards an amorphous phase which transforms at elevated temperatures to $\mathrm{Y}_{2} \mathrm{O}_{3}$. It does not occur in the present investigation. It just goes again to show that yttrium builds into the dawsonite structure. That is why the first yttrium containing phases that appear at elevated temperatures are yttrium aluminates (see the further text).

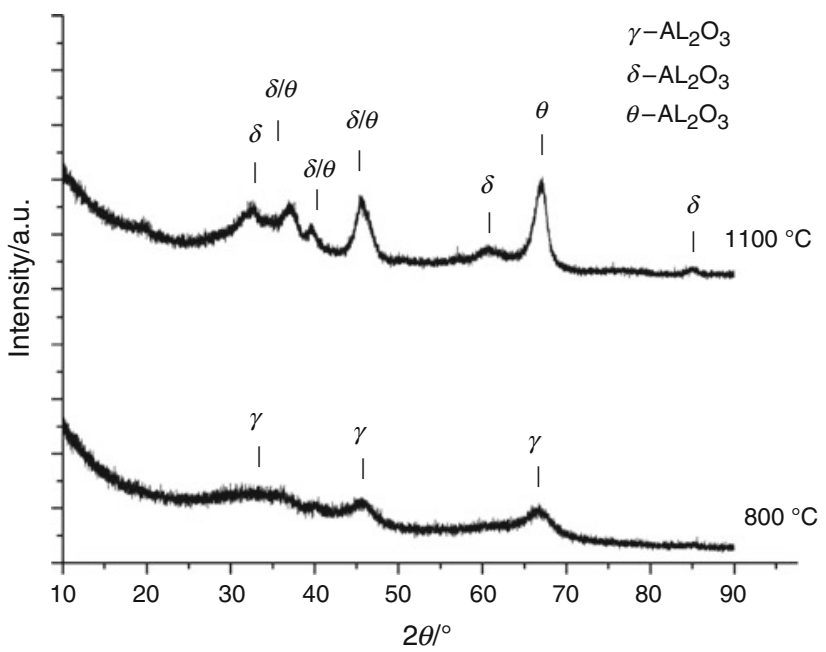

Fig. 4 X-ray diffraction patterns of the yttrium containing sample heated up to 800 and $1,100{ }^{\circ} \mathrm{C}$ 


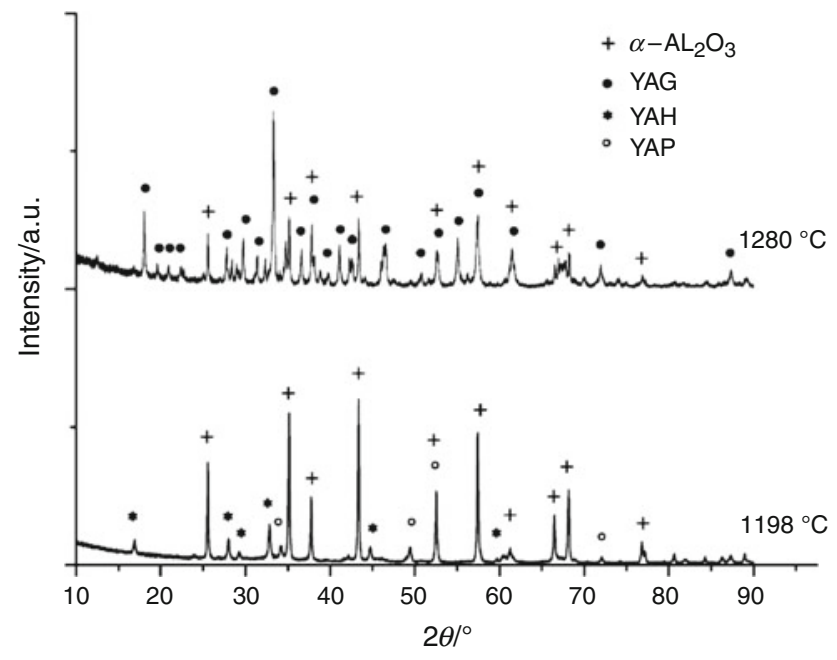

Fig. 5 X-ray diffraction patterns of the yttrium containing sample heated up to 1,185 and $1,280{ }^{\circ} \mathrm{C}$

The same technique as above was applied in the case of the highest temperature exothermic effect. Peak temperature in the case of yttria containing system corresponds to $1,231{ }^{\circ} \mathrm{C}$. Figure 5 shows $\mathrm{X}$-ray diffraction patterns of the sample heated up to 1,198 and $1,280{ }^{\circ} \mathrm{C}$, e.g., slightly higher and slightly lower than the peak temperature of the exothermic effect (Fig. 2a). The former ones indicate the existence of $\alpha-\mathrm{Al}_{2} \mathrm{O}_{3}$, hexagonal $\mathrm{YAlO}_{3}(\mathrm{YAH})$ and rhombohedra $\mathrm{YAlO}_{3}$ (YAP). The material calcined to $1,280{ }^{\circ} \mathrm{C}$ shows only $\alpha-\mathrm{Al}_{2} \mathrm{O}_{3}$ and $\mathrm{YAG}\left(\mathrm{Y}_{3} \mathrm{Al}_{5} \mathrm{O}_{12}\right)$. These facts lead us to the conclusion that the high temperature exothermic effect is caused by the $\alpha-\mathrm{Al}_{2} \mathrm{O}_{3}$ and yttrium aluminates crystallization. In the case of the system without yttrium additive the crystallization of $\alpha-\mathrm{Al}_{2} \mathrm{O}_{3}$ is responsible for the exothermic effect (Fig. 2b). We can only speculate why peak temperature in the case of the pure system is higher than in the system with yttrium additive. Presumably transformation of YAH and YAP to YAG adds energy to the system and by itself shifts crystallization of $\alpha-\mathrm{Al}_{2} \mathrm{O}_{3}$ towards lower temperatures in the system doped with yttrium. As it was found YAH and YAP transformations to YAG are exothermic ones $[4,6]$.

\section{Conclusions}

A mutual solution of $\mathrm{Al}\left(\mathrm{NO}_{3}\right)_{3} \mathrm{Y}\left(\mathrm{NO}_{3}\right)_{3}$ was introduced into $\left(\mathrm{NH}_{4}\right)_{2} \mathrm{CO}_{3}$. This procedure results in ammonium dawsonite precipitation with yttrium ions built into its structure. DSC/TG measurements at low temperature show an endothermic effect accompanied by weight loss and $\mathrm{H}_{2} \mathrm{O}, \mathrm{CO}_{2}$, and $\mathrm{NH}_{3}$ emission. At the end of this process $\gamma-\mathrm{Al}_{2} \mathrm{O}_{3}$ was found by the X-ray diffraction. At $1,100{ }^{\circ} \mathrm{C}$ $\gamma-\mathrm{Al}_{2} \mathrm{O}_{3}$ transforms to $\delta-\mathrm{Al}_{2} \mathrm{O}_{3}$ and $\theta-\mathrm{Al}_{2} \mathrm{O}_{3}$ with no traces of yttrium containing phase. The latter appears at $1,198{ }^{\circ} \mathrm{C}$ as YAH and YAP together with $\alpha-\mathrm{Al}_{2} \mathrm{O}_{3}$ and at $1,280{ }^{\circ} \mathrm{C}$ transforms to $\alpha-\mathrm{Al}_{2} \mathrm{O}_{3}+\mathrm{YAG}$ occurs.

Acknowledgements Research was financially supported by the Polish Ministry of Science and High Education under Grant NN 507 457737.

Open Access This article is distributed under the terms of the Creative Commons Attribution License which permits any use, distribution, and reproduction in any medium, provided the original author(s) and the source are credited.

\section{References}

1. Yalfani MS, Santiago M, Perez-Rairez J. In situ studies during thermal activation of dawsonite-type compounds to oxide catalysts. J Mater Chem. 2007;17:1222-9.

2. Moringa K, Torikai T, Nakagawa K, Jujino S. Fabrication of fine $\alpha-\mathrm{Al}_{2} \mathrm{O}_{3}$ powders by thermal decomposition of ammonium aluminum carbonate hydroxide (AACH). Acta Mater. 2000;48: 4735-41.

3. Wajler A, Tomaszewski H, Drożdż-Cieśla E, Weglarz H, Kaszkur Z. Study of magnesium spinel formation from carbonate precursors. J Eur Ceram Soc. 2008;28:2495-500.

4. Li J, Chen F, Liu W, Zhang W, Wang L, Ba X, Zhu Y, Pan Y, Guo J. Co-precipitation synthesis route to yttrium aluminum garnet (YAG) transparent ceramics. J Eur Ceram Soc. 2012 (in press).

5. Li J, Li J, Chen Q, Wu W, Xiao D, Zhu J. Effect of ammonium sulfate on the monodispersed $\mathrm{Y}_{3} \mathrm{Al}_{5} \mathrm{O}_{12}$ nanopowders synthesized by co-precipitant method. Powder Technol. 2012;212:46-50.

6. Li J-G, Ikegami T, Lee J-H, Mori T, Yajima Y. Co-precipitation synthesis and sintering of yttrium aluminum garnet (YAG) powders: the effect of precipitant. J Eur Ceram Soc. 2000;20: 2395-405.

7. Lach R, Haberko K, Bućko MM, Szumera M, Grabowski G. Ceramic matrix composites in the alumina/5-30 vol.\% YAG system. J Eur Ceram Soc. 2011;31:1889-95.

8. Lach R, Haberko K, Bućko MM. Alumina/YAG 20vol.\% composite. Synthesis by the co-precipitation method. In: Proceedings of the 12th conference of the European ceramic society, Stockholm. 2011.

9. Haberko K. Characteristics and sintering behaviour of zirconia ultrafine powders. Ceram Int. 1979;5:145-8.

10. Iga T, Kato S. Crystal structure of $\mathrm{NH}_{4}$-dawsonite. J Ceram Soc Jpn. 1978;86:509-12. 